\title{
SYNCHROTRON RADIATION DAMAGE TEST OF INSULATING MATERIALS IN THE TRISTAN MR
}

\author{
H. Mitsui, R. Kumazawa, T. Tanii, and T. Chugun \\ Toshiba Corporation \\ 2-4 Suehiro-cho, Tsurumi-ku, Yokohama-shi, 230 Japan \\ Y. Ohsawa, T. Ozaki, and K. Takayama \\ National Laboratory for High Energy Physics in Japan (KEK) \\ 1-1, Ohno, Tsukuba-shi, Ibaraki-ken, 305 Japan
}

Abstract

Irradiation test of typical insulating materials for an accelerator magnet was carried out, using actual radiation in the TRISTAN MR (main ring) which was operated at the highest radiation level in the accelerator society. Physical and chemical degradations of the insulating materials due to irradiation are quantitatively reported in this paper. Some suggestions on future insulating material and its manufacturing method are given.

\section{INTRODUCTION}

TRISTAN is an $\mathrm{e}^{+} \mathrm{e}^{-}$colliding beam accelerator with the collision energy in a range of $\sqrt{\mathrm{s}} \approx 60 \mathrm{GeV}$. The MR was first operated in October 1986 at the beam energy of $25 \mathrm{GeV}$. Since then the beam energy has been increased step by step from $25 \mathrm{GeV}$ to $30 \mathrm{GeV}$ by employing RF accelerating cavities [1]. Thereafter the radiation damage on accelerator components, such as signal cable for beam monitors, power cable for vacuum pumps, various electric circuit components, and exciting coil of magnets, has become increasingly serious [2].

Systematic studies of the radiation damage on electrically insulating materials used for particle accelerators are found in the literature [3]; meanwhile, same kind of tests were carried out in the TRISTAN MR [4] several years ago. However, the irradiation dose was limited below $100 \mathrm{MGy}$ for both cases. Radiation damage beyond this level is currently of big concem in the accelerator society because irradiation beyond $100 \mathrm{MGy}$ is likely to occur in localized regions of the existing machines. Under such a situation, results of the first systematic studies performed in this dose level are released.

\section{SPECIMENS}

Three types of insulating materials for an exciting coil as shown in Table 1 were chosen for the current study. Type A is the so-called VPI (vacuum-pressure-impregnation) insulation system which consists of glass-cloth reinforced mica-paper tape impregnated with epoxy resin. Type B is a resin-rich insulation system which is manufactured in the atmosphere, by molding BT (bismaleimide triazine) resin preimpregnated glass-cloth, by means of heat shrinkable tape. Type $C$ is another resin-rich insulation system which is manufactured under vacuum, by molding polyimide preimpregnated glass-cloth, with an asphalt compound.

For the purpose of knowing a change in their electrical properties such as $\tan \delta$, an aluminum bar with cross-section of $6(\mathrm{~mm}) \times 25(\mathrm{~mm})$ and total length of $160(\mathrm{~mm})$ was covered with each of these materials in the same manner as actual coils. To measure a change in their mechanical properties, on the other hand, samples were formed in a laminate by molding the tapes in the same manufacturing process as that of the bar coils. The plate sizes were $2 \mathrm{~mm}$ in thickness, $25 \mathrm{~mm}$ in width and $100 \mathrm{~mm}$ in length.

Table 1 Insulation constitution of test specimens.

\begin{tabular}{|c|l|l|l|}
\hline Type & Material & $\begin{array}{l}\text { Manufacturing } \\
\text { process }\end{array}$ & $\begin{array}{l}\text { Applied } \\
\text { machine }\end{array}$ \\
\hline A & $\begin{array}{l}\text { Epoxy/mica/ } \\
\text { E glass }\end{array}$ & VPI & $\begin{array}{l}\text { TRISTAN } \\
\text { main ring }\end{array}$ \\
\hline B & $\begin{array}{l}\text { BT resin/s } \\
\text { glass }\end{array}$ & $\begin{array}{l}\text { Heat shrinkable } \\
\text { tape-molding }\end{array}$ & PS ring \\
\hline C & $\begin{array}{l}\text { Polyimide/T } \\
\text { glass }\end{array}$ & $\begin{array}{l}\text { Vacuum-asphalt } \\
\text { pressure- } \\
\text { molding }\end{array}$ & None \\
\hline
\end{tabular}

E glass : Electric grade glass

S.T glass: Boron-free glass

\section{TEST BENCH}

All of test specimens were put in a radiation box located in the steering magnet of the normal section where the dose of $3.7-6.5 \times 10^{4} \mathrm{~Gy} / \mathrm{h}$, consisting of direct synchrotron radiation and its secondary, was seriously high in the MR. The dose has been calibrated with the thermo-luminescence dosimeter method [2] by employing a test beam with well monitored energy and current.

The samples taken out of the irradiation box at some fixed time period were subjected to the tests explained in the following section.

\section{TEST RESULTS AND DISCUSSIONS}

In Fig. 1, the magnitude of BDV (breakdown voltage) of the bar coils are shown as functions of dose. Fig. 2 shows the relationship between flexural strength of the laminate and dose. Fig. 3 is the relative dose dependence of residual BDV and flexural strength. The dose for halving BDV and flexural slrength, which is usually used as criteria for insulation design, is listed in Table 2. In the case of type $B$, the degradation of the residual BDV appears in the lower dose compared to that 
of the mechanical property; this is contrary to the popular view. At the highest irradiation level of $167 \mathrm{MGy}$, type A including mica reveals the highest BDV but the lowest flexural strength among three samples. In addition, it shows large swelling; it is understandable from speculation that the epoxy resin adjacently placed to the glass-cloth is decomposed into gas and the amount of gas increases with dose.

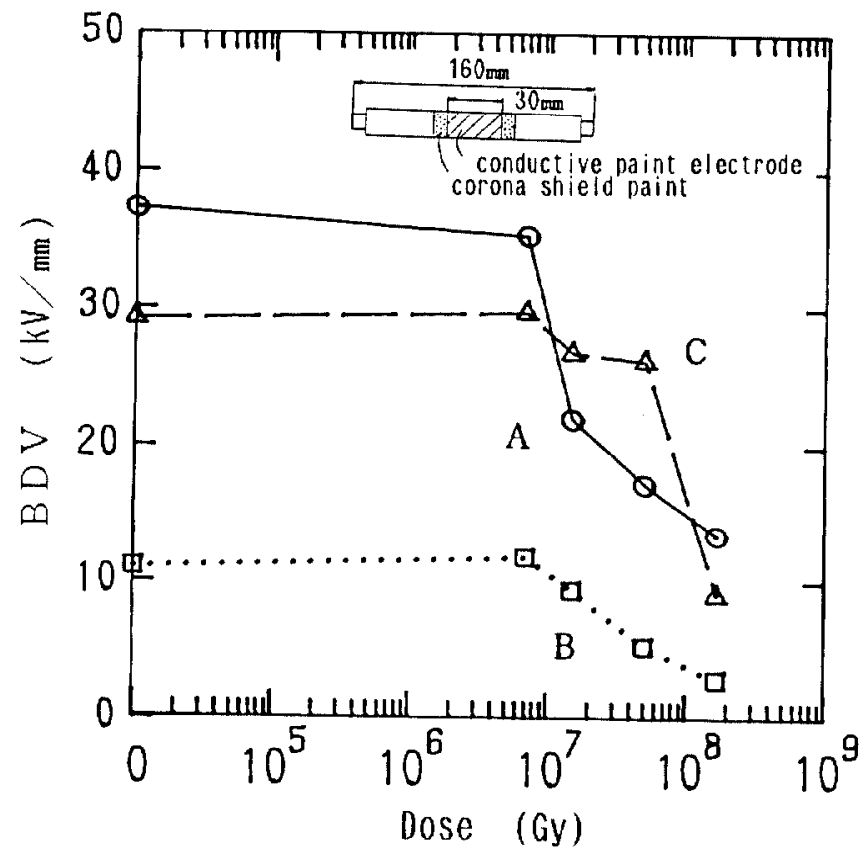

Fig. 1 Relationship between BDV of bar coils and dose.

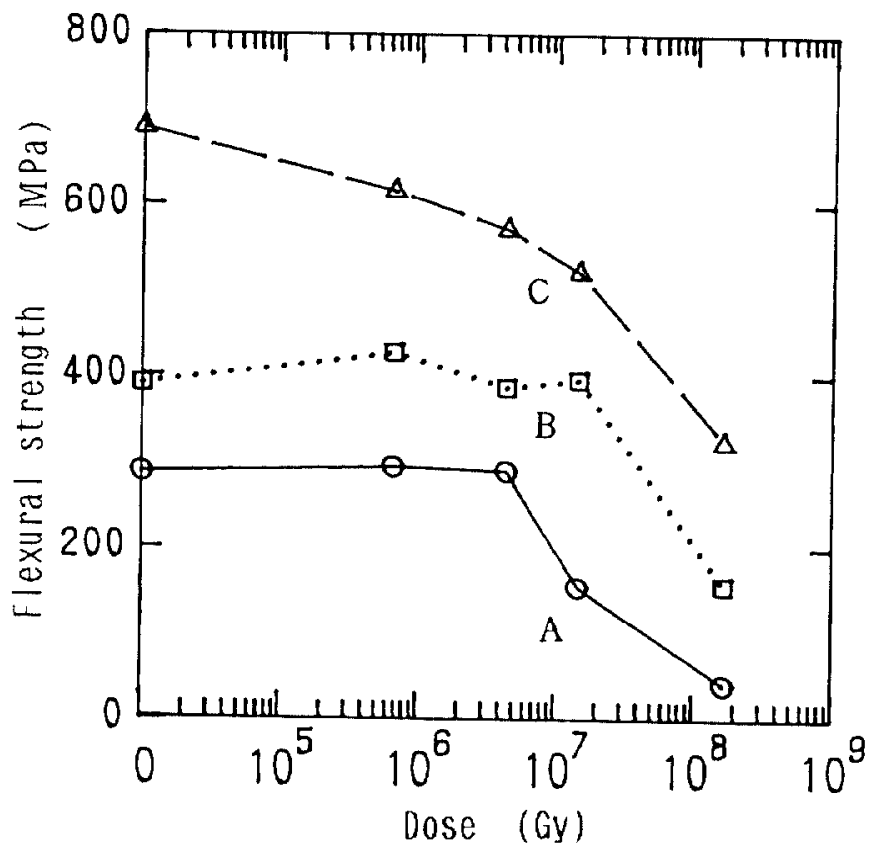

Fig. 2 Relationship between flexural strength of laminates and dose.
Table 2 Irradiation dose for halving BDV and flexural strength obtained from Fig. 3.

\begin{tabular}{|c|c|c|}
\hline Type & BDV & Flexural strength \\
\hline A & $3.3 \times 10^{7}$ & $1.9 \times 10^{7}$ \\
\hline B & $4.6 \times 10^{7}$ & $1.1 \times 10^{8}$ \\
\hline C & $1.1 \times 10^{8}$ & $1.3 \times 10^{8}$ \\
\hline
\end{tabular}

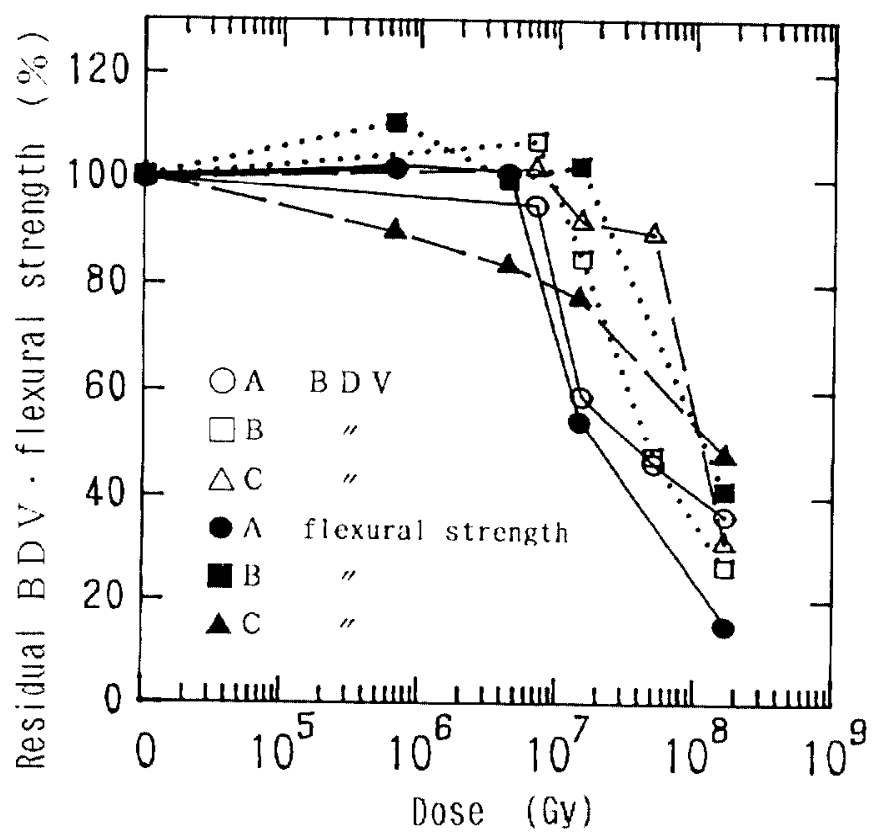

Fig. 3 Dose dependences of residual BDV and flexural strength obtained from the results shown in Fig. 1 and Fig. 2

Let's compare type B and type C which are the glasscloth reinforced resin-rich insulations without mica. Type $C$ is apparently superior to type $\mathrm{B}$ with respect to the BDV and flexural strength, as seen in Figs. 1 and 2. This can be attributed to the existence of voids in the insulating materials. The oxidation tends more to develop in the void contained insulating materials than in the void-free one. Type $\mathrm{C}$ is void-free because it was processed in vacuum by the asphaltcompound molding technique. type $\mathrm{B}$ was processed in the atmosphere by the heat shrinkable tape molding technique; therefore it contains voids.

It should be pointed out that in type B sample voids generate more easily than in type $\mathrm{C}$ with irradiation, as discussed below. Fig. 4 shows $\Delta \tan \delta$ characteristics as a function of dose. Where, $\Delta \tan \delta=(\tan \delta @ 3 \mathrm{kV}-\tan \delta @ 0.5 \mathrm{kV})$. The parameter $\Delta \tan \delta$ is known to reflect partial discharges in void. It is reasonable to regard $\Delta \tan \delta$ as a measure of the amount of voids. As seen in Fig. 4, $\Delta$ tan $\delta$ increases with dose in the lower dose region in type $B$ than in type $C$. This suggests that due to gas evolution by decompositions of the resin by irradiation, delaminations of the insulating materials 
occurred to generate voids. The down in $\Delta \tan \delta$ at $167 \mathrm{MGy}$ for type $\mathrm{B}$ is supposed that the puncture of the insulation occurred due to the increase of pressure in the closed void, and the void became open to the atmosphere resulting in decrease in volume.

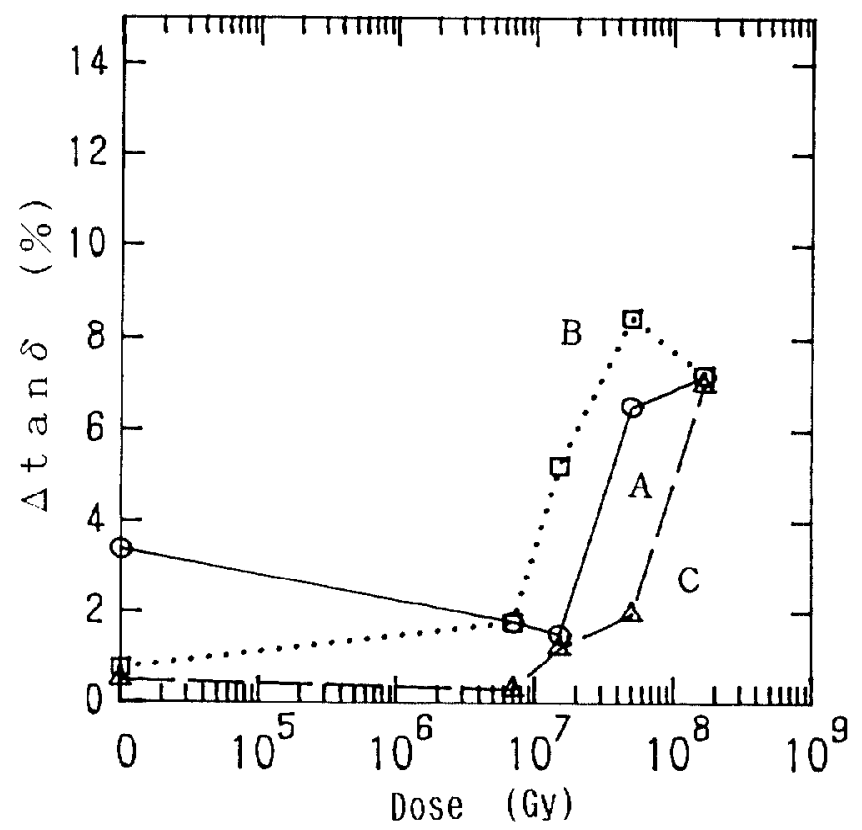

Fig. 4 Dose dependence of $\Delta \tan \delta$ of bar coils.

Fig. 5 shows the relationship between carbonyl absorbance and dose for all samples. Their features, except for the magnitude, are similar to each other. The carbonyl

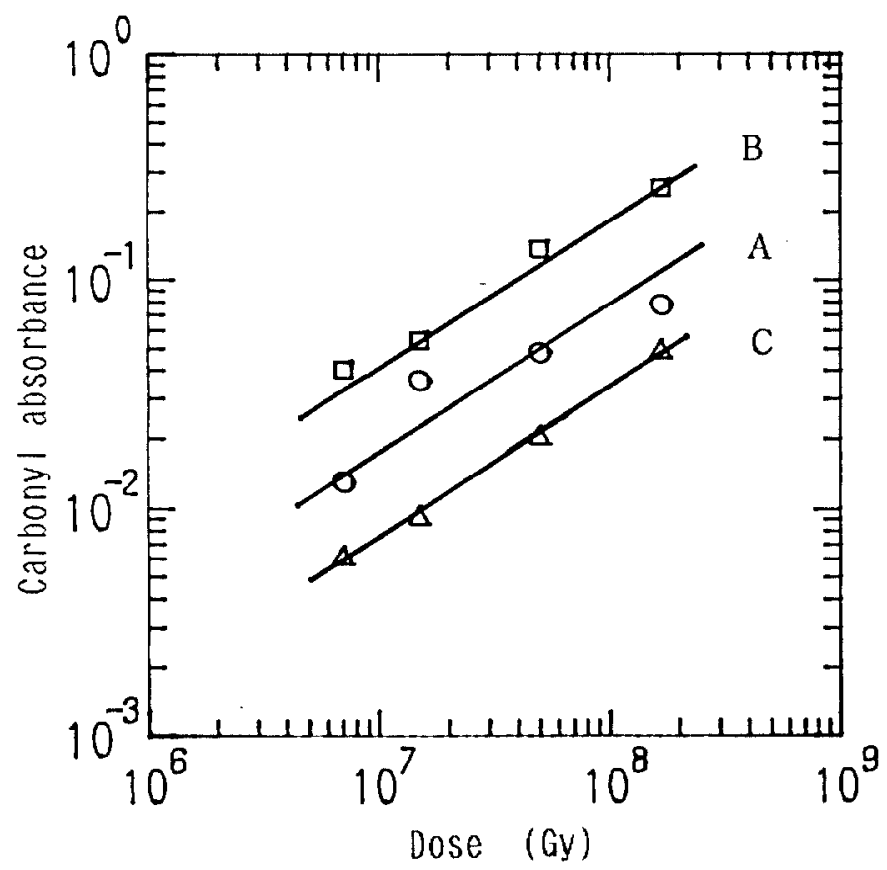

Fig. 5 Relationship between carbonyl absorbance and dose. absorbance is apparently proportional to dose. The increase of the carbonyl group should originate from the oxidation reactions and scissions of molecules of resin which are caused by the radiation. As seen in Figs. 4 and 5, the characteristics of samples for carbonyl absorbance qualitatively coincide with that for $\Delta \tan \delta$. Thus, carbonyl absorbance can be regarded as a useful index giving the size of chemical decomposition.

The authors arrived at a speculation that these oxidation reactions and delaminations degraded insulating materials, and thus decreased BDV and flexural strength; the voids took essential roles in the process.

\section{CONCLUSIONS}

From the irradiation tests of typical insulating materials for magnet, using actual radiation in the TRISTAN MR (up to 167 MGy at the highest), the following were made clear.

(1) Epoxy/glass-cloth/mica-tape insulation processed by the VPI method has higher BDV by the aid of mica tape; however its flexural strength remarkably degrades at the higher dose.

(2) The insulation processed by the asphalt pressure molding method under vacuum is far superior both in electrical stability and mechanical rigidity to the insulation processed by the heat-shrinkable tape molding method.

(3) The insulation processed by the heat-shrinkable tape molding method shows that the decrease in the BDV appears at a lower dose than for the flexural strength; this fact is contrary to the popular view.

(4) Carbonyl absorbance is a useful index to measure the size of chemical decomposition caused by irradiation.

As a concluding remark, studies of the manufacturing process as well as insulating materials themselves are, indeed, important in order to develop the higher radiation-resistant insulation.

\section{REFERENCES}

[1] Y. Kimura et al., Proceedings of the 6th Symposium Accelerator Science and Technology, Tokyo, 1987, pp1517.

[2] T. Momose et al., European Particle Accelerator Conference, Rome, 1988

[3] P. Beynel et al., CERN 82-10 (1982)

[4] T. Ozaki et al., Proc. AC89, 2015 2017 (1989) 